\title{
In Vitro Release and Bioavailability of Silybin from Micelle-Templated Porous Calcium Phosphate Microparticles
}

\author{
Yuan Zhu, ${ }^{1}$ Miaomiao Wang, ${ }^{1}$ Ya Zhang, ${ }^{1}$ Jin Zeng, ${ }^{1}$ E. Omari-Siaw, ${ }^{1}$ Jiangnan Yu, ${ }^{1}$ and Ximing Xu ${ }^{1,2,3}$
}

Received 3 August 2015; accepted 30 November 2015; published online 15 December 2015

ABSTRACT. Developing a promising carrier for the delivery of poorly water-soluble drugs, such as silybin, to improve oral absorption has become a very worthy of consideration. The goal of this study was to prepare a novel porous calcium phosphate microparticle using povidone-mixed micelles as template while evaluating its in vitro and in vivo properties with silybin as a model drug. The particle characterization, in vitro drug release behavior, and pharmacokinetic parameters of the prepared silybin-loaded calcium phosphate microparticle were investigated. The mean particle size was found to be $3.54 \pm 0.32 \mu \mathrm{m}$ with a rough surface porous structure. Additionally, the silybin-loaded calcium phosphate microparticle compared with the free silybin showed a prolonged 72 -h release in vitro and a higher $C_{\max }(418.5 \pm$ $23.7 \mathrm{ng} \mathrm{mL}^{-1}$ ) with $167.5 \%$ oral relative bioavailability. A level A in vitro-in vivo correlation (IVIVC), established for the first time, demonstrated an excellent IVIVC of the formulated silybin in oral administration. In conclusion, this povidone-mixed micelle-based microparticle was successfully prepared to enhance the oral bioavailability of silybin. Therefore, application of this novel porous calcium phosphate microparticle holds a significant potential for the development of poorly water-soluble drugs.

KEY WORDS: bioavailability; calcium phosphate; porous microparticles; povidone-mixed micelle; silybin.

\section{INTRODUCTION}

Calcium phosphate has been extensively researched as the biocompatible inorganic biomaterial for synthetic bone grafts (1) and non-viral vectors for gene delivery (2). Over the past decades, the application of porous calcium phosphate as carriers in drug delivery has attracted much attention due to significant advantages such as large specific surface area and high loading capacity for drug (3), protein $(4,5)$, or DNA molecules (6,7). Among the application methods which include micelle-templated synthesis $(8,9)$, emulsion process (10-12), and surfactant-assisted route $(13,14)$, micelletemplated synthesis technique has been the most widely used. To date, polymeric micelle templates have been successfully applied to the fabrication of many porous calcium phosphate carriers. One salient feature of such carriers prepared with micelle-templated method is the ease to tune size and morphology by adjusting the polymer combination, mineralization time, and solvent composition. Afterwards, the micelle

Yuan Zhu and Miaomiao Wang contributed equally to this work.

\footnotetext{
${ }^{1}$ Department of Pharmaceutics, School of Pharmacy, Center for Nano Drug/Gene Delivery and Tissue Engineering, Jiangsu University, Zhenjiang, 212001, People's Republic of China.

${ }^{2}$ Department of Pharmaceutics, School of Pharmacy, Center for Nano Drug/Gene Delivery and Tissue Engineering, Jiangsu University, Zhenjiang, 212013, People's Republic of China.

${ }^{3}$ To whom correspondence should be addressed. (e-mail: xmxu@ujs.edu.cn)
}

template can be removed by calcination or solvent evaporation, leading to a porous or hollow structure.

The key to a successful micelle-templated synthesis is to prepare a proper micelle as template. Our previous work on the polyvinylpyrrolidone (PVP)/sodium cholate/phospholipid mixed (povidone-mixed) micelle $(15,16)$ established it as a novel carrier which was good at improving the solubility and oral bioavailability of poorly water-soluble drugs. Also, the auxiliary material PVP, a water-soluble nonionic polymer, has a long history in pharmaceutical application as a delivery system for hydrophobic drugs (17). Besides, the bile salts have been shown to enhance the solubility of hydrophobic drugs $(18,19)$. Hence, with the aid of such a micelle system, a controlled architecture of calcium phosphate with porous or hollow structure could be designed to facilitate drug delivery. Thus, the present study aimed at obtaining a porous calcium phosphate carrier for hydrophobic drugs by a new type of polymeric micelle and focused on developing a promising oral carrier for potential applications to improve the delivery of poorly water-soluble drugs in vitro and in vivo.

Despite increasing interests of calcium phosphate carriers in drug delivery $(20,21)$, very limited numbers of studies regarding its oral administration exist. Therefore, to evaluate its drug release and oral administration efficiencies, silybin, a naturally occurring polyphenolic flavonoid extracted from the seed of the milk thistle (Silybum marianum) $(22,23)$, was incorporated into the calcium phosphate micron-sized carrier as a model drug in this work. Silybin has been widely used for the treatment of liver disorders $(24,25)$, such as chronic active 
hepatitis, hepatic cirrhosis, as well as alcohol-, drug-, and toxin-induced liver damage $(26,27)$.

Herein, attempts at preparing a novel calcium phosphate micron-sized carrier based on povidone-mixed micelle (16) to improve in vitro release and oral bioavailability of the poorly water-soluble drug, silybin, have been carried out in this work.

\section{MATERIALS AND METHODS}

\section{Materials}

Phospholipid was purchased from Taiwei Pharmaceutical Industry Co., Ltd (Shanghai, China). Sodium cholate, disodium hydrogen phosphate, and calcium chloride were obtained from Sinopharm Chemical Reagent Co., Ltd (Shanghai, China). PVP K30 of pharmaceutical grade (Mw 45,000) was purchased from Sunpower New Material Co., Ltd (Shanghai, China). Silybin (purity $\geq 98 \%$ ) was kindly provided by Zhongxing Pharmaceutical Industry Co., Ltd (Jiangsu, China). $\alpha$-Naphthol was purchased from Tianjin Chemical Reagent Factory (Tianjin, China). Other chemical reagents were of analytical grade or better. Male beagle dogs (2 years old, weighing $10.1 \pm 1.9 \mathrm{~kg}$ ) were purchased from Yadong Laboratory Animal Research Center (Jiangsu, China). All the experimental protocols involving animals in this study were evaluated and approved by the Ethics Committee of Jiangsu University on March 2, 2013. The number of the certification which verified approval of this study is 20130302-1.

\section{Preparation of Calcium Phosphate Microparticles}

Calcium phosphate microparticles were prepared according to our previous studies (28). In brief, absolute ethanol solution $(20 \mathrm{~mL})$ containing sodium cholate $(0.7 \mathrm{~g})$ and phospholipid $(0.3 \mathrm{~g})$ was added to $50 \mathrm{mM} \mathrm{CaCl} 2$ aqueous solution $(60 \mathrm{~mL})$ and stirred vigorously at $40^{\circ} \mathrm{C}$ for $10 \mathrm{~min} . \mathrm{Na}_{2} \mathrm{HPO}_{4}$ $(50 \mathrm{mM}, 40 \mathrm{~mL})$ and absolute ethanol solution $(20 \mathrm{~mL})$ containing PVP K30 (0.4 g) were added drop-wise to the mixture. The suspension obtained was then stirred at $600 \mathrm{rpm}$ for $12 \mathrm{~h}$. The resulting white precipitate was collected and washed thrice by centrifugation-redispersion cycles with deionized water and absolute ethanol. Finally, the collected precipitates were freeze-dried to obtain the powder of calcium phosphate microparticles.

\section{Preparation of Silybin-Loaded Calcium Phosphate Microparticles}

The calcium phosphate microparticles were suspended in deionized water to obtain a concentration of $50 \mathrm{mg} \mathrm{mL}^{-1}$. Then, a $100-\mathrm{mg} \mathrm{mL}^{-1}$ silybin solution was prepared using absolute ethanol as solvent. The calcium phosphate microparticles and silybin solution were mixed at the proportion of 2:1 $(v / v)$ at $37^{\circ} \mathrm{C}$ and stirred at $600 \mathrm{rpm}$ for $12 \mathrm{~h}$. After centrifugation for $10 \mathrm{~min}$ at $15,000 \mathrm{rpm}$ and washing three times with absolute ethanol, the silybin-loaded calcium phosphate microparticles were collected. The powders of silybin-loaded calcium phosphate microparticles were obtained by a freeze-drying process and kept at $4^{\circ} \mathrm{C}$ for further evaluation.

\section{Particle Size Analysis}

Dynamic light scattering measurement was carried out to determine the particle size distribution of calcium phosphate microparticle suspension in deionized water $(3 \mathrm{~mL}$, $10 \mathrm{mg} \mathrm{mL}{ }^{-1}$ ) using BIC90 Nanoparticle Size Analyzer (Brookhaven Instruments, USA) at $25^{\circ} \mathrm{C}$. The mean particle size was analyzed by the dispersion technology software (Brookhaven Instruments, USA). All assays were performed in triplicate.

\section{Scanning Electron Microscopy (SEM)}

The powders of calcium phosphate microparticles were platinum coated with thickness in the range of $3-5 \mathrm{~nm}$. The SEM images of calcium phosphate microparticles were recorded using a JSM 7001F scanning electron microscope (JEOL, Japan) at a working distance of $8 \mathrm{~mm}$ and an acceleration voltage of $15 \mathrm{kV}$.

\section{Fourier Transform Infrared Spectroscopy (FTIR)}

To confirm the successful incorporation of silybin, the FTIR spectral measurements were performed using a Nicolet spectrophotometer (Model Avatar 370, Milwaukee, WI, USA). The samples were finely ground with $\mathrm{KBr}$ to prepare the pellets under a hydraulic pressure of $8 \mathrm{mPa}$, and the spectra were scanned between 400 and $4000 \mathrm{~cm}^{-1}$.

\section{Drug Loading}

The silybin-loaded calcium phosphate microparticles were washed thrice with absolute ethanol to dissolve the unloaded silybin. The volume of the eluent was determined and, after diluting to a suitable concentration, the resulting ethanol solution was analyzed by UV at $288 \mathrm{~nm}$, according to the previous literature (29). The absorbance recorded was applied to a standard curve formula to calculate the concentration of silybin in the ethanol solution. The standard curve formula $(A=0.042236 C-0.0043510(n=6, r=0.99939)$ where $A$ was the absorbance at $288 \mathrm{~nm}$ and $C$ represented the concentration of silybin) was established by determining the absorbance of a series of standard silybin ethanol solutions $(1,5,10$, 15,20 , and $\left.30 \mu \mathrm{g} \mathrm{mL}^{-1}\right)$. The data of drug loading presented as mean of triplicate samples was calculated according to the following equation:

Drug loading $=100 \%\left(W_{1}-W_{2}\right) / W$

where $W$ was the total weight of drug-loaded calcium phosphate microparticles, $W_{1}$ was the weight of drug which was used to prepare the sample of silybin-loaded calcium phosphate microparticles, and $W_{2}$ was the weight of drug in the eluent.

\section{In Vitro Drug Release}

The in vitro release of silybin-loaded calcium phosphate microparticles and free silybin were investigated with a dialysis method in two different media, phosphate buffer solution 

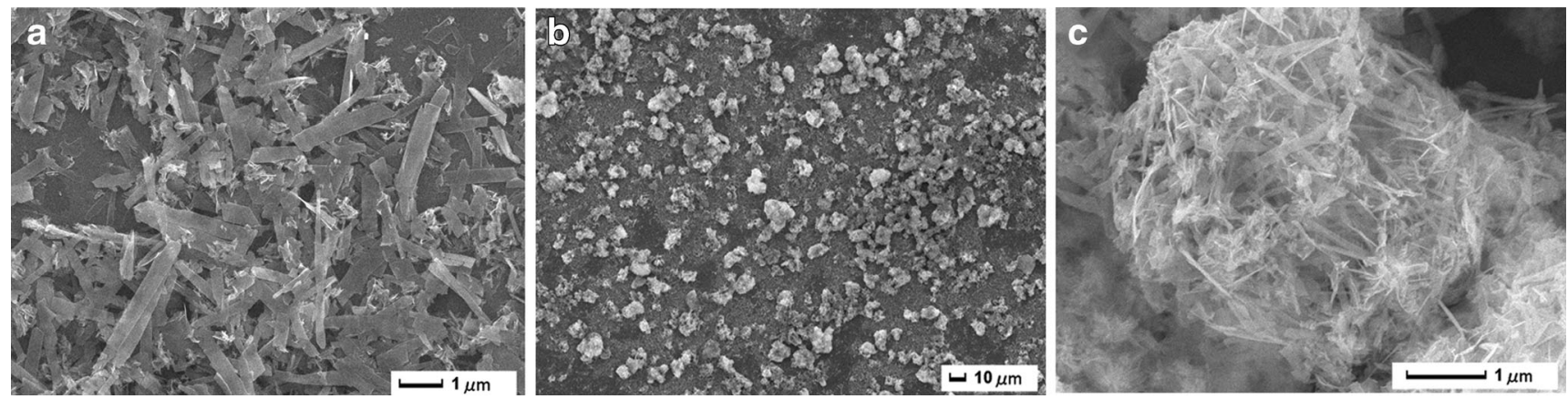

Fig. 1. Scanning electron micrograph of a calcium phosphate microparticles without micelle template, b porous calcium phosphate microparticles at $\times 1000$ magnification, and $\mathbf{c}$ calcium phosphate microparticles at $\times 10,000$ magnification

(pH 7.4) and $\mathrm{HCl}$ solution (pH 1.2), using a ZRS-8G dissolution test apparatus (Tianjin Tianda Tianfa, China). Sample powder $(50 \mathrm{mg})$ was dispersed in $1 \mathrm{~mL}$ of each dissolution medium, before placing in dialysis bag $(\mathrm{Mw} \sim 3500)$. The dialysis bag was placed in the basket before immersing in $900 \mathrm{~mL}$ of media at $37 \pm 0.5^{\circ} \mathrm{C}$ with a rotational paddle speed of $100 \pm$ $2 \mathrm{rpm}$. At settled time intervals $(0.5,1,2,3,6,8,12,24,36,48$, 60 , and $72 \mathrm{~h}$ ), the dissolution medium of $5 \mathrm{~mL}$ was withdrawn and replaced with equal volume of fresh medium (preheated to $37^{\circ} \mathrm{C}$ ). The samples at each time points were filtered through $0.45 \mu \mathrm{m}$ cellulose nitrate membranes for UV analysis at $288 \mathrm{~nm}$. The calibration tests made with UV absorption measurements of pure silybin at different $\mathrm{pH}$ values showed no change in the drug spectra. The cumulative release (\%) was calculated as the weight ratio of released silybin to total silybin. Data at each time point were presented as mean of triplicate samples.

\section{Bioavailability of Silybin-Loaded Calcium Phosphate Micro- particles in Beagle Dogs}

Four male beagle dogs were randomly and equally divided into two groups. The beagle dogs were housed individually and acclimatized in the laboratory for at least 1 week prior to testing. Each dog was fasted for $24 \mathrm{~h}$ with free access to water before the experiment. Capsules filled with silybin-loaded calcium phosphate microparticle (at a dose of $20 \mathrm{mg} \mathrm{kg}^{-1}$ silybin) and free silybin were orally administered to each group of dogs, respectively. The washout period between two consecutive treatments was 2 weeks. After oral administration, $2 \mathrm{~mL}$ of blood samples was collected from the jugular vein into a heparinized tube at each time point of $0.25,0.5,1$, $2,4,6,8,10,12$, and $24 \mathrm{~h}$. The plasma obtained after centrifugation $(10 \mathrm{~min}, 3000 \mathrm{rpm})$ was stored immediately at $-20^{\circ} \mathrm{C}$ until analysis. Silybin in $200 \mu \mathrm{L}$ of dog plasma was extracted by the addition of $20 \mu \mathrm{L}$ internal standard solution ( $\alpha$-naphthol, $10 \mu \mathrm{g} \mathrm{mL}{ }^{-1}$ in methanol), $200 \mu \mathrm{L} \mathrm{KH}_{2} \mathrm{PO}_{4}\left(0.2 \mathrm{~mol} \mathrm{~L}^{-1}\right.$,<smiles>COc1cc([C@H]2Oc3cc([C@H]4Oc5cc(O)cc(O)c5C(=O)[C@H]4O)ccc3O[C@@H]2CO)ccc1O</smiles>

Fig. 2. Chemical structure of isomeric silybin: a silybin A, b silybin B
pH 5), $20 \mu \mathrm{L}$ methanol, and $5 \mathrm{~mL}$ diethyl ether. The mixture was vortex-mixed thoroughly for $5 \mathrm{~min}$ and then centrifuged for $10 \mathrm{~min}$ at $3000 \mathrm{rpm}$. The organic phase (4 mL) was quantitatively transferred and evaporated to dryness under a nitrogen flow at $37^{\circ} \mathrm{C}$. The dried residue was re-suspended in $100 \mu \mathrm{L}$ mobile phase. The re-suspended solution $(20 \mu \mathrm{L})$ was injected into an HPLC system. A Symmetry C18 reserved phase analytical column $(5 \mu \mathrm{m}, 4.6 \mathrm{~mm} \times 150 \mathrm{~mm}$, Waters, USA) set at $38^{\circ} \mathrm{C}$ was employed. The mobile phase was a mixture of methanol and $0.05 \mathrm{~mol} \mathrm{~L}{ }^{-1} \mathrm{KH}_{2} \mathrm{PO}_{4}(v / v 1: 1, \mathrm{pH}$ adjusted to 3.8 with phosphoric acid) at $1.0 \mathrm{~mL} \mathrm{~min}^{-1}$ flow rate. The UV detection wavelength was set at $288 \mathrm{~nm}$. The calibration was linear over a range from 10 to $1000 \mathrm{ng} \mathrm{mL}-1$ $(R=0.0014297 C-0.010905)$ with a correlation coefficient $(r)$ 0.99851 . The LOD of current assay based on $S / N=3$ was $3 \mathrm{ng} \mathrm{mL} \mathrm{m}^{-1}$ in plasma. The method recoveries were all above $80 \%$ at high, middle, and low concentrations, and the intraand inter-day variation was below to $10.0 \%$. Since silybin is an isomeric compound, two peaks with the retention time were detected (30). The sum of the area of the two peaks was calculated for analysis. The ratio of peak area of silybin over that of the internal standard was used for quantitative analysis. And the method was validated by adding various quantities of silybin to blank beagle dog plasma. These calibrations were subjected to the entire analytical procedure, so as to test the linearity, precision, and accuracy of the method. The peak concentration $\left(C_{\max }\right)$ and peak time $\left(T_{\max }\right)$ were derived directly from the experimental points. The relative bioavailability and other pharmacokinetic parameters were calculated using the program BAPP 2.3 (supplied by the Center of Drug Metabolism and Pharmacokinetics, China Pharmaceutical University) by non-compartmental analysis.

\section{In Vitro-In Vivo Correlation}

In this study, a plot of percent dissolved in vitro vs. percent absorbed in vivo input at various time points up to<smiles>COc1cc([C@@H]2Oc3cc([C@@H]4Oc5cc(O)cc(O)c5C(=O)[C@H]4O)ccc3O[C@H]2CO)ccc1O</smiles> 


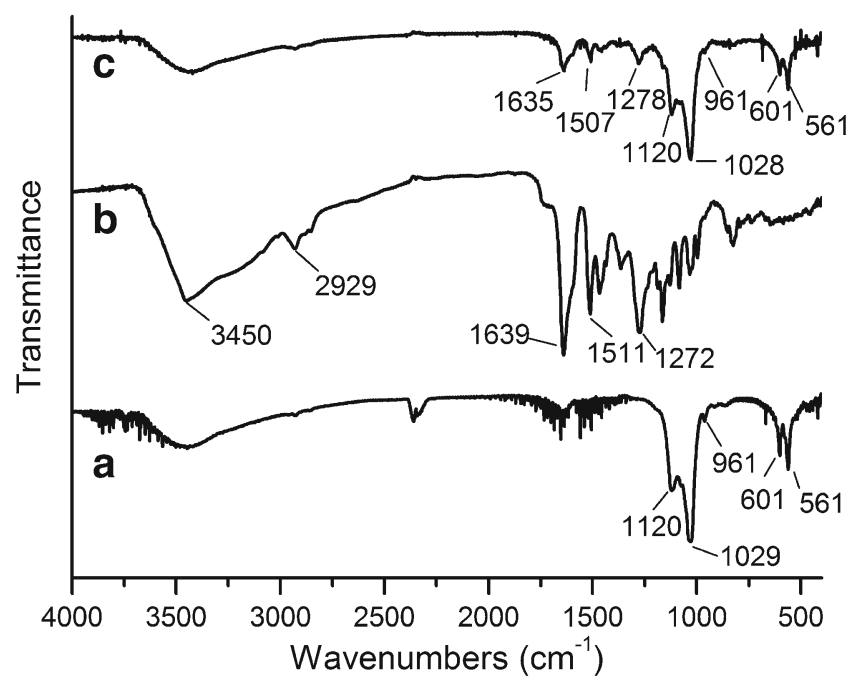

Fig. 3. FTIR spectra of a calcium phosphate microparticles, b silybin, and $\mathbf{c}$ silybin-loaded calcium phosphate microparticles

$24 \mathrm{~h}$ was constructed to develop a level A correlation as classified by US Food and Drug Administration (31). Also, the correlation between in vitro release in two dissolution media ( $\mathrm{pH} 7.4$ phosphate buffer solution and $\mathrm{pH} 1.2 \mathrm{HCl}$ solution) and the in vivo absorption was respectively established.

\section{Statistical Analysis}

All the experimental data were expressed as mean \pm standard deviation (SD), and the statistical differences between the different groups were evaluated by Student's $t$ test. The SPSS statistic software (SPSS version 15.0, SPSS Inc., Chicago, IL, USA) was used. Difference between two groups was considered to be statistically significant at $p<0.05$.

\section{RESULTS}

\section{Characterization of Calcium Phosphate Microparticles}

Figure 1 illustrates SEM of the surface and integral morphology of the calcium phosphate microparticles. Significant differences were observed between Fig. $1 \mathrm{a}$ and $\mathrm{b}$, which depicted the calcium phosphate microparticles without the micelle template and the porous calcium phosphate microparticles, respectively. Apparently, the calcium phosphate microparticles exhibited spherical or ellipsoidal shape with rough surfaces (Fig. 1b). A closer view of the micronsized calcium phosphate carrier revealed a nest-like structure on the surface with particle size around $3.5 \mu \mathrm{m}$ (Fig. 1c). This indicated an irregular porous structure resulting from the crystal assembling based on the

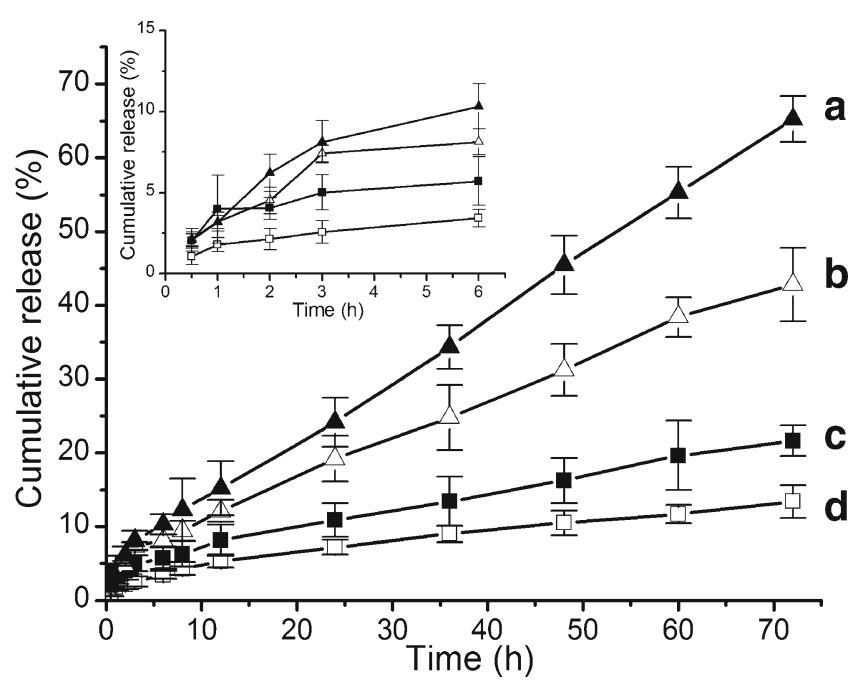

Fig. 4. In vitro release profiles of silybin-loaded calcium phosphate microparticles in a pH 7.4 phosphate buffer saline, b $\mathrm{pH} 1.2 \mathrm{HCl}$, and release profiles of free silybin in $\mathbf{c}$ pH 7.4 phosphate buffer saline and d pH $1.2 \mathrm{HCl}($ mean $\pm \mathrm{SD}, n=3)$ 


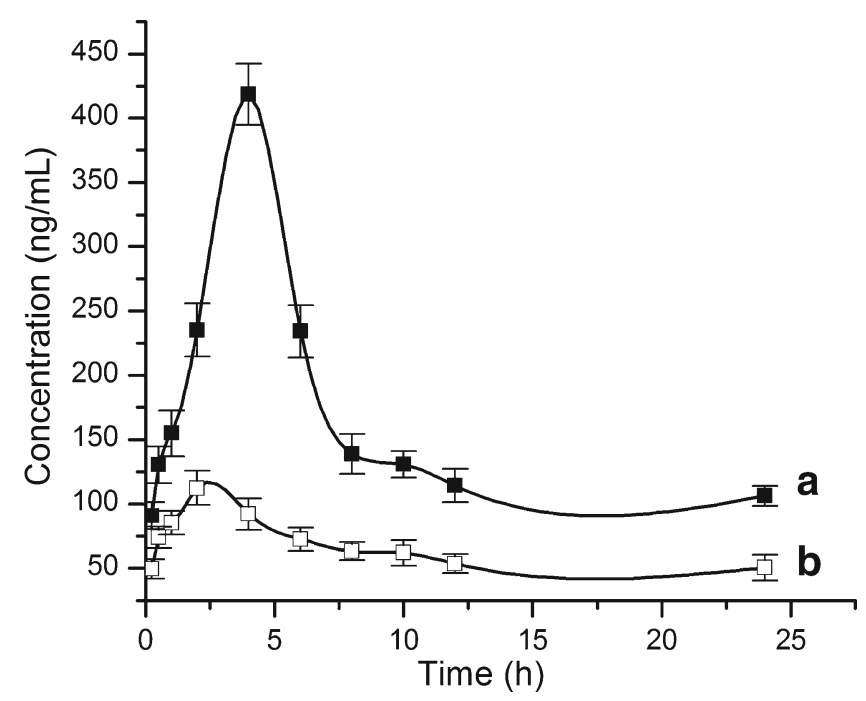

Fig. 5. Mean plasma concentration-time profiles of silybin in beagle dogs after oral administration of a silybin-loaded calcium phosphate microparticles and $\mathbf{b}$ free silybin equivalent to $20 \mathrm{mg} \mathrm{kg}^{-1}$ of silybin $($ mean $\pm \mathrm{SD}, n=4)$

povidone-mixed micelle template. From the structure of silybin presented in Fig. 2 and the FTIR spectra shown in Fig. 3, characteristic phosphate group bands (Fig. 3a) occurred at wave numbers 561, 601,961, 1029, and $1120 \mathrm{~cm}^{-1}$ for the calcium phosphate microparticles. The bands at 1029 and $1120 \mathrm{~cm}^{-1}$ could be assigned to the components of triply degenerate $v_{3}$ antisymmetric $\mathrm{P}-\mathrm{O}$ stretching mode. The non-degenerate $\mathrm{P}-\mathrm{O}$ symmetric stretching mode $v_{2}$ was detected at $961 \mathrm{~cm}^{-1}$. The bands at 601 and $561 \mathrm{~cm}^{-1}$ could also be attributed to the components of the triply degenerated $v_{1} \mathrm{O}-\mathrm{P}-\mathrm{O}$ bending mode. The FTIR spectra in Fig. 3b indicated characteristic group bands at wave numbers 1272, 1511, 1639, 2929, and $3450 \mathrm{~cm}^{-1}$ for free silybin. The broader band at $3450 \mathrm{~cm}^{-1}$ was attributed to the hydroxyl groups, while the bands at 2929, 1639, 1272, and $1511 \mathrm{~cm}^{-1}$ were assigned to $\mathrm{C}-\mathrm{H}, \mathrm{C}=\mathrm{O}, \mathrm{C}-\mathrm{O}$, and $\mathrm{C}=\mathrm{C}$ stretching modes, respectively, which proved the existence of benzene ring. The FTIR spectra in Fig. 3c showed both characteristic group bands of calcium phosphate and silybin. The bands at wave numbers 561, 601, 961, 1028, and $1120 \mathrm{~cm}^{-1}$ in the spectra indicated the presence of calcium phosphate. The characteristic groups of silybin could be assigned to the bands at wave numbers 1278, 1507, and $1635 \mathrm{~cm}^{-1}$. The most noticeable change in the FTIR spectra shown in Fig. 3c was the disappearance of the $\mathrm{O}-\mathrm{H}$ $\left(3450 \mathrm{~cm}^{-1}\right)$ and $\mathrm{C}-\mathrm{H}\left(2929 \mathrm{~cm}^{-1}\right)$ bands as well as the significant decrease of transmittance values at silybin characteristic group bands $\left(1278,1507\right.$, and $\left.1635 \mathrm{~cm}^{-1}\right)$. These results suggest that silybin was loaded into the porous structure of calcium phosphate microparticles. The content of loaded silybin was calculated to be $44.6 \pm 1.2 \%$.

\section{In Vitro Drug Release}

Figure 4 showed the dissolution profiles of silybin-loaded calcium phosphate microparticles and free silybin in $\mathrm{HCl}$ solution ( $\mathrm{pH}$ 1.2) and phosphate buffer solution ( $\mathrm{pH}$ 7.4).Less than $21.7 \%$ of the free silybin (suspended in $1 \mathrm{~mL}$ of the dissolution medium) in the dialysis bag was released within $72 \mathrm{~h}$ as compared to $65.2 \%$ from the calcium phosphate microparticles. The respective cumulative drug release of $13.4 \%$ and $42.8 \%$ from free silybin and the microparticle in $\mathrm{HCl}$ solution ( $\mathrm{pH}$ 1.2) within $72 \mathrm{~h}$ was relatively slower as compared with that from the phosphate buffer saline ( $\mathrm{pH} 7.4)$ over the same period. These results suggest that the release of silybin in this study was $\mathrm{pH}$-dependent, with higher $\mathrm{pH}$ values leading to faster drug release.

Table I. The Main Pharmacokinetic Parameters of Silybin-Loaded Calcium Phosphate Microparticles and Free Silybin in Beagle Dogs $(n=4)$

\begin{tabular}{llll}
\hline Parameters & Unit & $\begin{array}{c}\text { Silybin-loaded calcium } \\
\text { phosphate microparticles }\end{array}$ & Silybin \\
\hline$t_{1 / 2}$ & $\mathrm{~h}$ & $36.3 \pm 3.1$ & $34.1 \pm 1.4$ \\
MRT & $\mathrm{h}$ & $44.9 \pm 5.6$ & $41.8 \pm 2.1$ \\
$C_{\max }$ & $\mathrm{ng} \mathrm{mL}$ & $418.5 \pm 23.7$ & $112.4 \pm 8.4$ \\
$T_{\max }$ & $\mathrm{h}$ & 4 & 2 \\
$\mathrm{AUC}_{0-\tau}$ & $\mathrm{ng} \mathrm{mL}$ & $3821.4 \pm 267.4$ & $1529.0 \pm 105.6$ \\
$\mathrm{AUC}_{0-\infty}$ & $\mathrm{ng} \mathrm{mL}$ & $4374.2 \pm 344.1$ & $2611.3 \pm 153.6$ \\
\hline
\end{tabular}

Data are shown as mean $\pm \mathrm{SD}$

$M R T$ mean residence time, $A U C$ area under curve 


\section{Bioavailability}

In vivo pharmacokinetic study for free silybin and silybinloaded calcium phosphate microparticles was conducted in beagle dogs. Plasma concentration versus time profiles of silybin following oral administration of silybin-loaded calcium phosphate microparticles and free silybin are depicted in Fig. 5. The pharmacokinetic parameters simulated by noncompartmental model using software program BAPP 2.3 are also shown in Table I. As illustrated in the profile, the average value of $C_{\max }$ after oral administration of silybin-loaded calcium phosphate microparticles was $418.5 \pm 23.7 \mathrm{ng} \mathrm{mL}^{-1}$ with $T_{\max }$ of about $4 \mathrm{~h}$ as compared with $C_{\max }$ of $112.4 \pm$ $8.4 \mathrm{ng} \mathrm{mL}{ }^{-1}$ and $T_{\max }$ of about $2 \mathrm{~h}$ from the free silybin. In addition, the relative bioavailability of silybin-loaded calcium phosphate microparticles in contrast with free silybin was about $167.5 \%$.

\section{In Vitro-In Vivo Correlation}

In this study, the correlation between in vitro and in vivo data for the prepared calcium phosphate microparticles was investigated. A level A correlation (32), i.e., a point-to-point relationship between in vitro dissolution and in vivo absorption, was established in $\mathrm{HCl}$ solution $(\mathrm{pH} 1.2)$ and phosphate buffer solution ( $\mathrm{pH}$ 7.4). As can be seen from Fig. 6, an excellent correlation was obtained with $r=0.98917$ for the phosphate buffer solution and $r=0.98737$ for $\mathrm{HCl}$ solution.

\section{DISCUSSION}

Povidone-mixed micelle system was initially designed to improve the solubility and oral bioavailability of poorly soluble drugs. PVP is a water-soluble nonionic polymer, which has a long history of use in pharmaceutical applications as a delivery system for poorly soluble drugs (33). Addition of PVP has been shown to increase the solubility and dissolution rates of certain poorly soluble drugs (34). In this study, the povidone-mixed micelle system was adopted innovatively as a new type of template to fabricate the calcium phosphate micron-sized carrier, which was incorporated with the hydrophobic drug, silybin, to evaluate oral bioavailability. As shown in Fig. 6, SEM images demonstrated the calcium phosphate carrier was well dispersed as individual particles. The particle size $(3.5 \mu \mathrm{m})$ observed from the SEM was consistent with that determined by the particle detector. Furthermore, the calcium phosphate micron-sized carrier exhibited spherical or ellipsoidal shape with a rough surface, which suggested an irregular porous structure, thus proving that the micelle template was removed by solvent evaporation over a gentle temperature condition of $40^{\circ} \mathrm{C}$. As shown in Fig. 6, the FTIR spectra confirmed the existence of calcium phosphate. The disappearance and decrease in spectra of drug-loaded calcium phosphate carrier at certain group bands of silybin indicated the incorporation of silybin into the porous structure.

As pointed out in our previous study, the dissolution of free silybin was $\mathrm{pH}$-dependent which increased with increasing $\mathrm{pH}(15,16)$. In the present work, the drug release behavior of calcium phosphate carrier was conducted in different $\mathrm{pH}$ solution. It can be seen from Fig. 6 that the dissolution profile exhibited a faster release from the calcium phosphate carrier
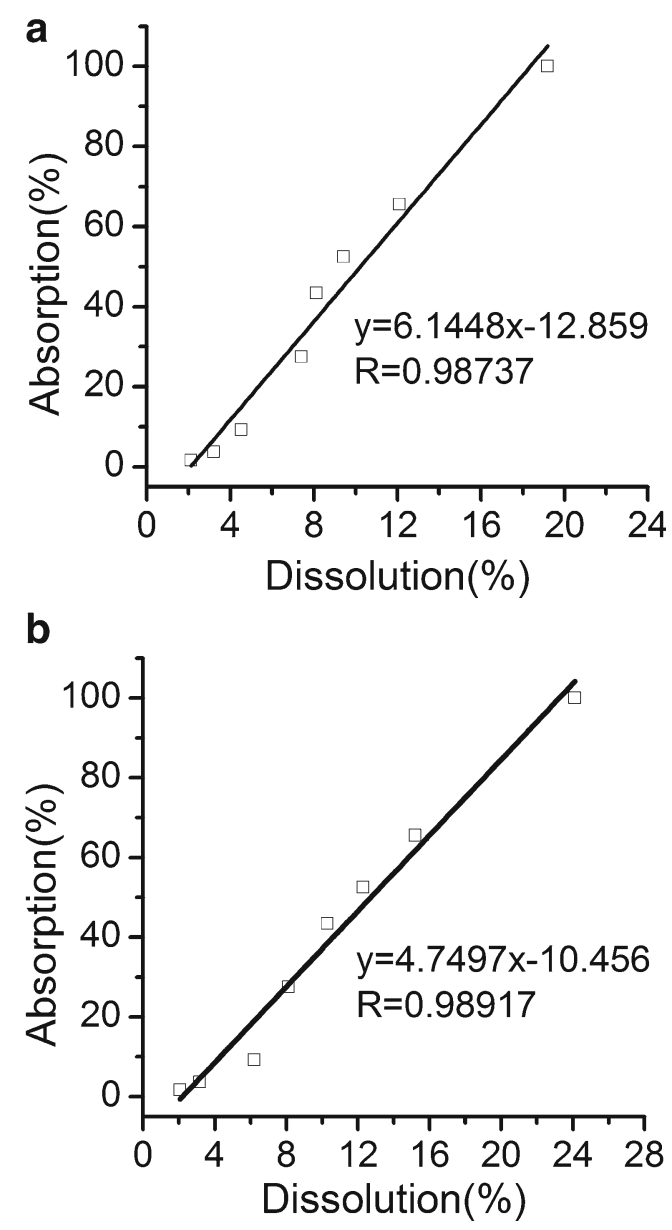

Fig. 6. Correlations between in vitro dissolution fractions and in vivo absorption fractions in two dissolution media. a pH $1.2 \mathrm{HCl}$ solution. b pH 7.4 phosphate buffer solution

than free silybin, while the both release accelerated with increasing $\mathrm{pH}$. The release behavior of silybin from the calcium phosphate microparticles was consistent with our previous findings. Therefore, the $\mathrm{pH}$-dependent behavior might indicate the removal of templated micelles. The pH-dependent behavior of silybin-loaded calcium phosphate microparticles could mainly be attributed to the silybin itself. The dissolution rate from calcium phosphate carriers was markedly different due to the different templates involved, some exhibited a very fast release behavior (35) while others exhibited a slow release behavior (3).

The pharmacokinetics of silybin-loaded calcium phosphate carrier and free silybin after orally administrated to beagle dogs were also investigated in this work. As observed from the profile of plasma concentration versus time depicted in Fig. 6 and the pharmacokinetic parameters shown in Table I, free silybin exhibited a very low bioavailability, which was in conformity with the results previously reported $(36,37)$. Meanwhile, the clinical efficacy of silybin is discounted by its poor water solubility, which result in poor oral absorption and bioavailability. Additionally, obvious differences between free silybin and silybin-loaded calcium phosphate carrier were found with respect to the delayed $T_{\max }$ from 2 to $4 \mathrm{~h}$. Moreover, the peak concentration of silybin release was approximately 3.7-fold of the free silybin after it had been 
incorporated into the calcium phosphate carrier. The main reason for the delay in $T_{\max }$ may be ascribed to the materials which we used for preparing the calcium phosphate microparticles. After the drug was incorporated into this carrier, it was protected by the microparticle matrix from the rapid degradation at acidic $\mathrm{pH}$ conditions. Notably, a tiny peak was observed at $10 \mathrm{~h}$, which may be due to the effect of bile salt via the enterohepatic circulation, as evidenced by $\mathrm{Wu}$ et al. (38). The relative bioavailability of $167.5 \%$ for silybin-loaded calcium phosphate carrier was dramatically enhanced compared to the free silybin. However, no significant difference was found in $t_{1 / 2}$ and MRT between the two experimental groups. As we know, the micellar system has been extensively investigated due to its advantage in improving the solubility and enhancing the oral bioavailability of poorly water-soluble drug. In our experiment, the calcium phosphate microparticle designed from povidone/ sodium cholate/phospholipid mixed micelles was successfully prepared, and the drug was proven to be incorporated into the porous structure after the removal of the micellar template, thus leading to prolonged release in vitro and enhanced absorption in vivo. On the other hand, the improved oral bioavailability of silybin-loaded microparticle might be attributed to enhanced silybin solubility in the gastrointestinal tract and relatively small size (39). Additionally, the drug was expected to be highly dispersed with high drug loading content in the prepared microparticle system due to the porous structure of the calcium phosphate microparticle.

The in vitro-in vivo correlation analysis of silybin-loaded calcium carbonate nanoparticles in two different media (phosphate buffer solution ( $\mathrm{pH}$ 7.4) and $\mathrm{HCl}$ solution $(\mathrm{pH} 1.2)$ ) showed an excellent linear relationship, with no significant influences of different $\mathrm{pH}$ values. This excellent correlation is quite important since it could suggest the possibility to predict in vivo pharmacokinetic behavior through the observed in vitro release profiles (40).

\section{CONCLUSION}

In summary, a novel porous calcium phosphate microparticle based on povidone/sodium cholate/phospholipid mixed micelles was prepared successfully for the first time. The pharmacokinetic study in beagle dogs showed the enhanced oral bioavailability facilitated by the prepared microparticle. The findings support the ability of porous calcium phosphate microparticle to improve solubility and oral bioavailability, thus advancing the literature of drug delivery for poorly water-soluble drugs.

\section{ACKNOWLEDGMENTS}

This work was supported by the National Natural Science Foundation of China (30472098), China Postdoctoral Science Foundation funded project (2015M571700), College Natural Science Research Foundation of Jiangsu Province (14KJB350002), and Research Foundation for Distinguished Scholars (15JDG074). This work was also funded by the Priority Academic Program Development of Jiangsu Higher Education Institutions. The authors are grateful to Emmanuel Omari-Siawat of Jiangsu University for correcting the English grammar. The authors also thank the University Ethics Committee for the kind guidance in the animal experiments.

\section{COMPLIANCE WITH ETHICAL STANDARDS}

Conflict of Interest

competing interests.

The authors declare that they have no

\section{REFERENCES}

1. Bohner M, Galea L, Doebelin N. Calcium phosphate bone graft substitutes: failures and hopes. J Eur Ceram Soc. 2012;32(11):2663-71.

2. Nouri A, Castro R, Santos JL, Fernandes C, Rodrigues JHT. Calcium phosphate-mediated gene delivery using simulated body fluid (SBF). Int J Pharm. 2012;434(434):199-208.

3. QL T, YJ Z, J W, F C, SW C. Calcium phosphate drug nanocarriers with ultrahigh and adjustable drug-loading capacity: one-step synthesis, in situ drug loading and prolonged drug release. Nanomedicine: nanotechnology, Biology, $\mid$ s\&lsmedicine. 2011;7(4):428-434.

4. Azevedo HS, Leonor IB, Alves CM, Reis RL. Incorporation of proteins and enzymes at different stages of the preparation of calcium phosphate coatings on a degradable substrate by a biomimetic methodology. Mater Sci Eng C. 2005;25(2):169-79.

5. Majid K, Tseng MD, Baker KC, Reyes-Trocchia A, Herkowitz HN. Biomimetic calcium phosphate coatings as bone morphogenetic protein delivery systems in spinal fusion. Spine J. 2011;11(6):560-7.

6. Li J, Chen YC, Tseng YC, Mozumdar S, Huang L. Biodegradable calcium phosphate nanoparticle with lipid coating for systemic siRNA delivery. J Control Release. 2010;142(3):416-21.

7. Pittella F, Miyata K, Maeda Y, Suma T, Watanabe S, Chen Q, et al. Pancreatic cancer therapy by systemic administration of VEGF siRNA contained in calcium phosphate/chargeconversional polymer hybrid nanoparticles. J Control Release. 2012;161(3):868-74.

8. Asim N, Radiman S, Yarmo MA, Golriz MSB. Vanadium pentoxide: synthesis and characterization of nanorod and nanoparticle V2O5 using CTAB micelle solution. Microporous Mesoporous Mater. 2009;120(120):397-401.

9. Dasgupta S, Bandyopadhyay ASB. Reverse micelle-mediated synthesis of calcium phosphate nanocarriers for controlled release of bovine serum albumin. Acta Biomater. 2009;5(8):3112-21.

10. Chen BH, Chen KI, Ho ML, Chen HN, Chen WC, Wang CK. Synthesis of calcium phosphates and porous hydroxyapatite beads prepared by emulsion method. Mater Chem Phys. 2009;113(1):365-71.

11. Lai C, Tang SQ, Wang YJ, Wei K. Formation of calcium phosphate nanoparticles in reverse microemulsions. Mater Lett. 2005;59(2):210-4.

12. Fujiwara M, Shiokawa K, Morigaki K, Tatsu Y, Nakahara Y. Calcium phosphate composite materials including inorganic powders, BSA or duplex DNA prepared by $\mathrm{W} / \mathrm{O} / \mathrm{W}$ interfacial reaction method. Mater Sci Eng C. 2008;28:280-8.

13. Schmidt SM, McDonald J, Pineda ET, Verwilst AM, Chen Y, Josephs R, et al. Surfactant based assembly of mesoporous patterned calcium phosphate micron-sized rods. Microporous Mesoporous Mater. 2006;94:330-8.

14. Zhang J, Jiang D, Chen Z, Huang Z. Synthesis of calcium phosphate fluoride hybrid hollow spheres. Mater Lett. 2013;91(3):358.

15. Jiang-nan YU, Yuan ZHU, Li WANG, et al. Enhancement of oral bioavailability of the poorly water-soluble drug silybin by sodium cholate/ phospholipid-mixed micelles. Acta Pharmacol Sin. 2010;31(6):759-64.

16. Yuan Z, Yu J, Tong S, Li W, Min P, Xia C, et al. Preparation and in vitro evaluation of povidone-sodium cholate-phospholipid mixed micelles for the solubilization of poorly soluble drugs. Arch Pharm Res. 2010;33(6):911-7.

17. Sun N, Wei X, Wu B, Jian C, Yi L, Wei W. Enhanced dissolution of silymarin/polyvinylpyrrolidone solid dispersion pellets prepared by a one-step fluid-bed coating technique. Powder Technol. 2008;182(1):72-80. 
18. Dongowski G, Fritzsch B, Giessler J, Hartl A, Kuhlmann O, Neubert RH. The influence of bile salts and mixed micelles on the pharmacokinetics of quinine in rabbits. Eur J Pharm Biopharm. 2005;60(1):147-51.

19. Hammad MA, Müller BW. Increasing drug solubility by means of bile salt-phosphatidylcholine-based mixed micelles. Eur J Pharm Biopharm Off J Arbeitsgemeinschaft Für Pharm Verfahrenstechnik E V. 1998;46(3):361-7.

20. Peter B, Pioletti DP, Laïb S, Bujoli B, Pilet P, Janvier P, et al. Calcium phosphate drug delivery system: influence of local zoledronate release on bone implant osteointegration. Bone. 2005;36(1):52-60.

21. Tang QL, Zhu YJ, Wu J, Chen F, Cao SW. Calcium phosphate drug nanocarriers with ultrahigh and adjustable drug loading capacity: one-step synthesis, in-situ drug loading and prolonged drug release. Nanomedicine Nanotechnol Biol Med. 2011;7(4):428-34.

22. Agarwal R, Katiyar SK, Lundgren DW, Mukhtar H. Inhibitory effect of silymarin, an anti-hepatotoxic flavonoid, on 12-Otetradecanoylphorbol-13-acetate-induced epidermal ornithine decarboxylase activity and mRNA in SENCAR mice. Carcinogenesis. 1994;15:20.

23. Flora K, Hahn M, Rosen H, Benner K. Milk thistle (Silybum marianum) for the therapy of liver disease. Am J Gastroenterol. 1998;93(2):139-43. 21.

24. Loguercio C, Andreone P, Brisc C, Brisc MC, Bugianesi E, Chiaramonte $\mathrm{M}$, et al. Silybin combined with phosphatidylcholine and vitamin $\mathrm{E}$ in patients with nonalcoholic fatty liver disease: a randomized controlled trial. Free Radic Biol Med. 2012;52(9):1658-65. 22.

25. Tedesco D. Effects of silymarin, a natural hepatoprotector, in periparturient dairy cows. J Dairy Sci. 2004;87(7):2239-2247. 23.

26. Ligeret H, Brault A, Vallerand D, Haddad Y, Haddad PS. Antioxidant and mitochondrial protective effects of silibinin in cold preservation-warm reperfusion liver injury. J Ethnopharmacol. 2008;115(3):507-14. 24.

27. Abenavoli L, Capasso R, Milic NFC. Milk thistle in liver diseases: past, present, future. Phytother Res Ptr. 2010;24(10):1423-32. 25

28. Zhu Y, Zhang J, Fu M, Zeng J, Omari-Siaw E, Xu XM. Calcium carbonate nanoparticles templated by mixed polymeric micelles: characterization, in vitro drug release and oral bioavailability in beagle dogs. Latin American Journal of Pharmacy. 2014;33. 26.
29. Chen L, Zhu H, Yang S, Zhou B, You F, Yan X. Nanostructured calcium phosphate carriers for deliver of poor water-soluble drug silybin. Materials Letters. 2015:252-255. 27.

30. Usman M, Ahmad M, Dayo A, Madni A, Ali L, Yousuf M, et al. Effect of \&BETA;-Glucuronidase on extraction efficiency of silymarin from human plasma samples using validated HPLCUV analysis. Trop J Pharm Res. 2012;11(1):84-90.

31. Bssman J, Reppas C. In vitro-in vivo correlations for lipophilic, poorly water-soluble drugs. Eur J Pharm Sci. 2000;11:S73-80. 29.

32. Zhu Y, Peng W, Zhang J, Wang M, Firempong CK, Feng C, et al. Enhanced oral bioavailability of capsaicin in mixed polymeric micelles: preparation, in vitro and in vivo evaluation. J Funct Foods. 2014;8(3):358-66. 30.

33. Modi A, Tayade P. Enhancement of dissolution profile by solid dispersion (kneading) technique. Aaps Pharmscitech. 2006;7(3):E87-92.

34. Ahire BR, Rane BR, Bakliwal SR, Pawar SP. Solubility enhancement of poorly water soluble drug by solid dispersion techniques. Int J Pharmtech Res. 2010;3:2007-15.

35. Feng Y, Guo H, Zhang H, He X. Polymeric micelle-templated synthesis of hydroxyapatite hollow nanoparticles for a drug delivery system. Acta Biomater. 2010;6(6):2212-8.

36. Morazzoni P, Magistretti MJ, Giachetti C, Zanolo G. Comparative bioavailability of Silipide, a new flavanolignan complex, in rats. Eur J Drug Metab Pharmacokinet. 1992;17(1):39-44.

37. Wei Y, Ye X, Shang X, Peng X, Bao Q. Enhanced oral bioavailability of silybin by a supersaturatable self-emulsifying drug delivery system (S-SEDDS). Colloids Surf A Physicochem Eng Asp. 2012;396(7):22-8.

38. Wu W, Wang Y, Que L. Enhanced bioavailability of silymarin by self-microemulsifying drug delivery system. Eur J Pharm Biopharm. 2006;63(3):288-94.

39. Dou J, Zhang H, Liu X, Zhang M, Zhai G. Preparation and evaluation in vitro and in vivo of docetaxel loaded mixed micelles for oral administration. Colloids Surf B: Biointerfaces. 2014;114(2):20-7.

40. Borkar N, Xia D, Holm R, Gan Y, Müllertz A, Yang M, et al. Investigating the correlation between in vivo absorption and in vitro release of fenofibrate from lipid matrix particles in biorelevant medium. Eur J Pharm Sci. 2013;51(1):204-10. 